\title{
Modelo de escoamento superficial em bacia experimental da Reserva Florestal Adolpho Ducke
}

\begin{abstract}
Arí de Oliveira MARQUES FILHO ${ }^{1}$, Sávio José Filgueiras FERREIRA², Sebastiāo Átila Fonseca MIRANDA³
RESUMO

Neste estudo, a experimentação e a modelagem hidrológica de eventos de precipitação transformada em escoamento superficial em sistemas naturais de floresta são investigadas, contemplando os seguintes tratamentos: construção de algoritmo computacional iterativo de otimização para a identificação do hidrograma unitário médio (função de transferência chuva-descarga) da bacia e para o cálculo das precipitações efetivas adequadas à cada evento chuva-escoamento; aplicação da metodologia à bacia hidrográfica do igarapé Bolívia, situada no interior da Reserva Florestal Adolpho Ducke; análise e interpretação do algoritmo criado, enfocando a sua convergência e o significado dos resultados desse processo de otimização; e comparação com outros estudos em pequenas bacias da Amazônia Central. O período de medidas de chuva e de vazóes estende-se de julho de 2004 a setembro de 2006, incluindo a fase de preparação da curva-chave do igarapé Bolívia e a formação de um conjunto amplo e diversificado de eventos de chuva e de escoamento no curso d'água.
\end{abstract}

PALAVRAS-CHAVES: precipitação, escoamento superficial, simulação hidrológica, Amazônia.

\section{Surface runoff model in the Reserva Florestal Adolpho Ducke experimental watershed}

\section{ABSTRACT}

In this study, experimentation and hydrologic modeling of rainfall events transformed into runoff in natural forest systems, are investigated, including the following treatments: construction of an iterative optimization computational algorithm to identify the average unity hydrograph (rain-discharge transfer function) of the watershed, and to compute the effective rainfalls adequate to each discharge-rainfall event; applying the methodology to the Igarapé Bolívia watershed, which is located inside the Adolpho Ducke Forest Reserve; analysis and interpretation of the established algorithm, focusing on its convergence and on the significance of the results of this optimization process; and comparison with other studies in small watersheds of Central Amazonia. Rainfall and runoff measurements were made from July 2004 to September 2006, including the preparation phase of the level-discharge curve of the Igarapé Bolívia and the making of a large and diversified set of rainfall and runoff events.

KEYWORDS: rainfall, runoff, hydrologic simulation, Amazonia.

1 Instituto Nacional de Pesquisas da Amazônia. E-mail: ari@inpa.gov.br

2 Instituto Nacional de Pesquisas da Amazônia. E-mail: savio@inpa.gov.br

${ }^{3}$ Instituto Nacional de Pesquisas da Amazônia. E-mail: atila@inpa.gov.br 


\section{INTRODUÇÃO}

A transformação da precipitação em escoamento numa bacia hidrográfica tem sido um tema tratado e discutido para a construçáo de uma teoria adequada, tanto em seus aspectos conceituais como em seus aspectos práticos. O desenvolvimento de uma teoria geral para explicar essas transformaçóes considera a bacia hidrográfica, com suas características físicas próprias e a sua cobertura vegetal, como sendo um sistema hidrológico linear ou não-linear, que produz uma resposta em forma do escoamento no curso d'água, provocada por eventos de precipitaçáo simples ou compostos, distribuídos na bacia. Os aspectos gerais desses processos físicos e dos modelos hidrológicos que os representam, a conceituação do hidrograma unitário como sendo o operador da transformação chuva-escoamento no sistema, a identificação dos efeitos combinados de armazenamento em distintos compartimentos do sistema e de translação pelos canais (cursos d'água) sobre a precipitaçáo para gerar o escoamento no curso d'água, foram desenvolvidos em vários estudos (Dooge, 1959; Nash, 1959; Dooge, 1973), formando em seu conjunto a teoria geral do hidrograma unitário para sistemas hidrológicos. No contexto de pequenas bacias hidrográficas em áreas de floresta, Hewlett \& Hibbert (1967) descreveram o conceito de área variável de contribuição para a formação do escoamento superficial e subsuperficial nesses sistemas naturais, permitindo o refinamento e a flexibilização interpretativa da simulação hidrológica nesses ambientes.

A identificação do hidrograma unitário adequado para uma dada bacia hidrográfica foi sendo aperfeiçoada com a evolução das técnicas numéricas computacionais e dos processadores que as executam. A expressão matricial das transformaçôes da chuva em escoamento foi inicialmente utilizada por Newton $\&$ Vinyard (1967) para produzir o hidrograma unitário médio do sistema. Esses procedimentos de manipulação matricial para estimar o operador do sistema foram retomados por Diskin \& Boneh (1975), num contexto já consolidado e reconhecido, tendo como critério de otimizaçáo a minimização da soma dos desvios quadrados entre as ordenadas dos hidrogramas observado e modelado. Observaçóes simultâneas de chuva e de escoamento constituem o material observacional necessário; a priori, precisa ser conhecida para o local em estudo uma função que separe a precipitação total em duas parcelas: precipitação efetiva - que gera o escoamento superficial (rápido), e infiltração - que alimenta o escoamento subterrâneo (lento); um método de separação do escoamento subterrâneo é também necessário para obter por diferença, as ordenadas do escoamento superficial. As operaçóes de otimização referidas acima começam a ser aplicadas sobre o conjunto assim formado de precipitaçóes efetivas e de escoamento superficial.

A extensão natural dos procedimentos descritos anteriormente consiste em juntar num único tratamento, as determinaçôes das precipitaçóes efetivas e do hidrograma unitário da bacia, partindo-se de um conjunto amplo de observaçóes de precipitação total média sobre a bacia e do escoamento correspondente, observado na seção de controle no curso d'água. As taxas de infiltração no solo da bacia ficam determinadas, ao longo do tempo em cada evento chuva-escoamento, pela simples diferença entre a chuva total e chuva efetiva. O método iterativo proposto por Duband $e t$ al. (1993), para a identificação do hidrograma unitário e da precipitaçáo efetiva, pertence a essa classe de estudos. Uma análise detalhada sobre diferentes aspectos desse estudo foi apresentada por Nalbantis et al. (1995). A aplicação desse método na bacia representativa de Juatuba, Minas Gerais, foi apresentada por Maia et al. (2006), contendo já modificaçôes na forma de calcular o hidrograma unitário e aproveitando os conceitos de modelos auto-regressivos.

Nesse contexto de modelagem hidrológica em bacias hidrográficas, os objetivos do presente estudo são compostos pelos seguintes tratamentos e aplicaçôes: construção de algoritmo iterativo computacional para a identificaçáo do hidrograma unitário médio e para o cálculo das precipitaçôes efetivas adequadas à cada evento chuva-escoamento, tendo como base um conjunto de medidas de precipitação total e de escoamento para a bacia em estudo; aplicaçấo da metodologia à bacia hidrográfica do igarapé Bolívia, situada no interior da Reserva Florestal Ducke; análise e interpretação de diferentes aspectos do algoritmo criado, enfocando a sua convergência para diferentes distribuiçóes iniciais de precipitação e o significado dos resultados desse processo de otimização; e comparaçáo dos resultados com estudos similares em pequenas bacias da Amazônia Central.

\section{MATERIAL E MÉTODOS}

\section{ÁREA DE ESTUDO E SISTEMA DE MEDIDAS HIDROLÓGICAS}

O sistema de medidas hidrológicas foi instalado em julho de 2004 na bacia hidrográfica do igarapé Bolívia, localizado na zona sul da Reserva Florestal Adolpho Ducke - macrofragmento de floresta com uma área de $100 \mathrm{~km}^{2}(10 \times 10 \mathrm{~km})$ em Manaus, 02 53' S e 59० 58' W (Figura 1).

As observaçôes de precipitação e de escoamento na bacia hidrográfica do igarapé Bolívia foram iniciadas em julho de 2004. Os níveis d'água são medidos por um linígrafo de pressáo conectado a um sistema de aquisição de dados da Campbell - CR510. O conjunto da experimentação hidrológica está inserido em projetos de pesquisa financiado pelo Fundo Setorial de Recursos Hídricos e pelo CNPq.

O clima da área foi definido a partir de uma série de dados climatológicos, observados na Estaçáo Climatológica da Reserva Ducke no período de 1965 a 1994. As normais extraídas desse conjunto de dados apontam a existência de duas 


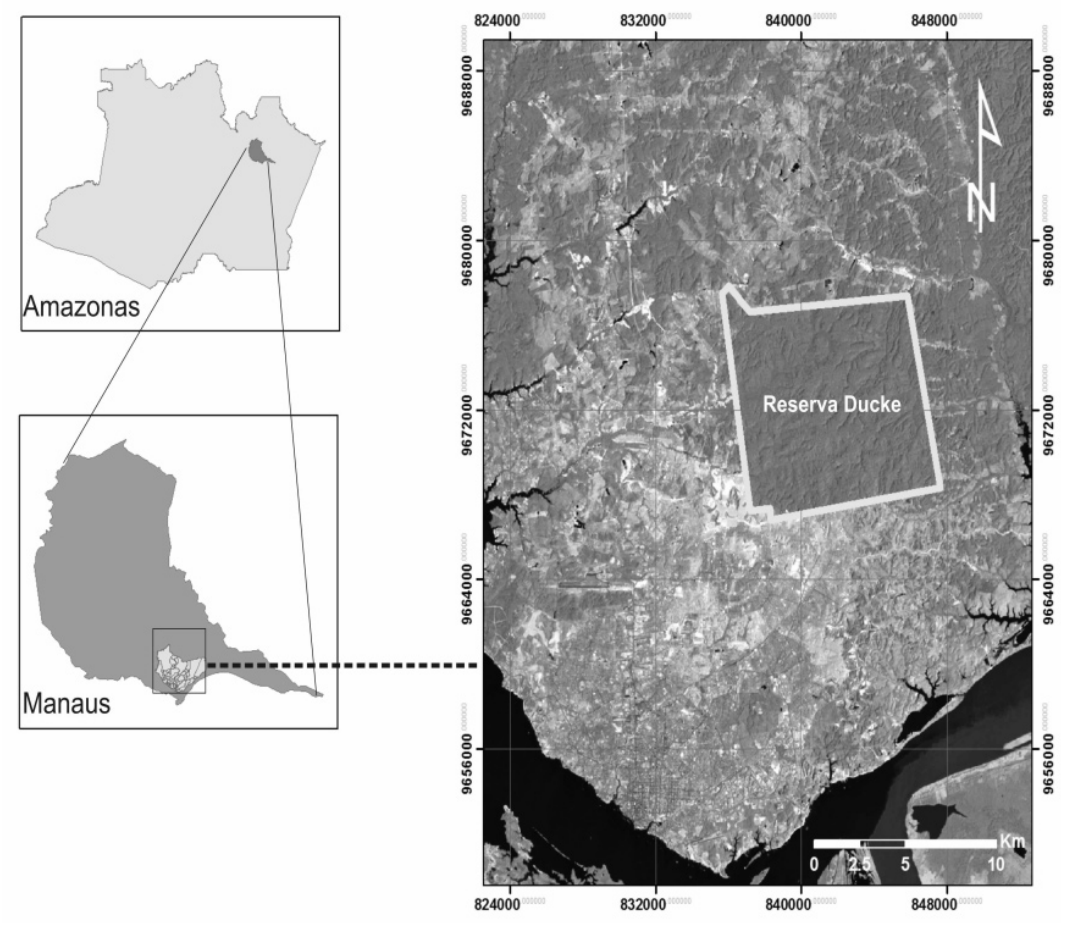

Figura 1 - Mapa de localização do experimento na Reserva Florestal Adolpho Ducke. Fonte: http://siglab.inpa.gov.br

estaçóes anuais: uma seca, no período de junho a novembro, com uma normal de precipitação mínima mensal de $93 \mathrm{~mm}$, em julho; e uma estaçáo chuvosa, no período de dezembro a maio, com normal de precipitação máxima mensal de 299 $\mathrm{mm}$, em fevereiro. As temperaturas apresentam média diária anual de $26,7^{\circ} \mathrm{C}$ com uma amplitude média de $9,6^{\circ} \mathrm{C}$; a maior amplitude térmica ocorre em setembro $\left(11,1^{\circ} \mathrm{C}\right)$ e a menor amplitude ocorre em abril $\left(8,2^{\circ} \mathrm{C}\right)$; os meses de setembro e outubro são os mais quentes, com temperaturas máximas de $33{ }^{\circ} \mathrm{C}$ e o mês mais frio em julho com temperatura mínima média de $21,3{ }^{\circ} \mathrm{C}$; a umidade relativa do ar apresenta médias mensais acima de 80,5 ; o mês de setembro apresenta a menor média (84\%) e o mês de maio a maior (91\%) (Marques Filho \& Dallarosa, 2000).

\section{MÉTODO DE IDENTIFICAÇÃO DO HIDROGRAMA UNITÁRIO E DE PRECIPITAÇÕES EFETIVAS}

As transformações de precipitações em escoamento nos cursos d'água em uma bacia hidrográfica podem ser descritas pela integral de convolução expressa na equação 1 , desde que o meio físico aproxime-se do comportamento de um sistema hidrológico linear.

$$
y(t)=\int_{0}^{t \leq t_{0}} x(\tau) h_{0}(t-\tau) d \tau
$$

sendo, $y(t)$ - vazão na seção de controle do curso d'água na saída da bacia;

$\mathrm{x}(\tau)$ - precipitação efetiva ocorrida sobre a bacia: $0 \leq \mathrm{x}(\tau)<\mathrm{x}_{\text {total }}(\tau)$.

$\mathrm{h}_{0}(t-\tau)$ - hidrograma unitário $: \int_{0}^{\infty} h_{0}(\tau) d \tau=1$

$\mathrm{t}_{0}$ - duração da precipitação efetiva.

A expressão adequada ao tratamento de precipitaçóes efetivas e de descargas, quando observadas como valores médios para um dado intervalo de tempo, é a forma discreta da operação de convolução, conforme representada na equação 2 ,

$$
\begin{gathered}
y_{i}=\sum_{j=f_{1 i}\left(N_{h}\right)}^{f_{2 i}\left(N_{x}\right)}\left(x_{j} h_{i-j+1}\right)=\sum_{k=f_{1 i}\left(N_{x}\right)}^{f_{2 i}\left(N_{h}\right)}\left(h_{k} x_{i-k+1}\right) \\
f_{1 i}(n)=\max (1, i-n+1) \\
f_{2 i}(n)=\min (i, n)
\end{gathered}
$$

na qual, a função $h_{(\ldots)}$ representa o hidrograma unitário em forma de histograma e os limites dos somatórios são funçóes dependentes do total de ordenadas das precipitaçóes efetivas, $\mathrm{N}_{\mathrm{x}}$, e do total de ordenadas do hidrograma unitário, $\mathrm{N}_{\mathrm{h}}$. O total de ordenadas do hidrograma observado, $\mathrm{N}_{\mathrm{y}}$, está associado aos totais anteriores, ou $\mathrm{N}_{\mathrm{y}}=\mathrm{N}_{\mathrm{x}}+\mathrm{N}_{\mathrm{h}}-1$. 
A estrutura básica da equação 2 constitui o ponto de partida dos métodos de identificação de hidrograma unitário e das precipitaçôes efetivas para uma bacia hidrográfica, em conformidade aos estudos de Newton \& Vinyard (1967), Diskin \& Boneh (1975), Duband et al. (1993), entre outros. Os procedimentos de otimização adotados no manuseio das observaçôes hidrológicas para gerar as funçóes indicadas acima representam as diferenças notáveis entre esses estudos. As duas versôes matriciais da equação 2 são expandidas segundo as seguintes expressōes,

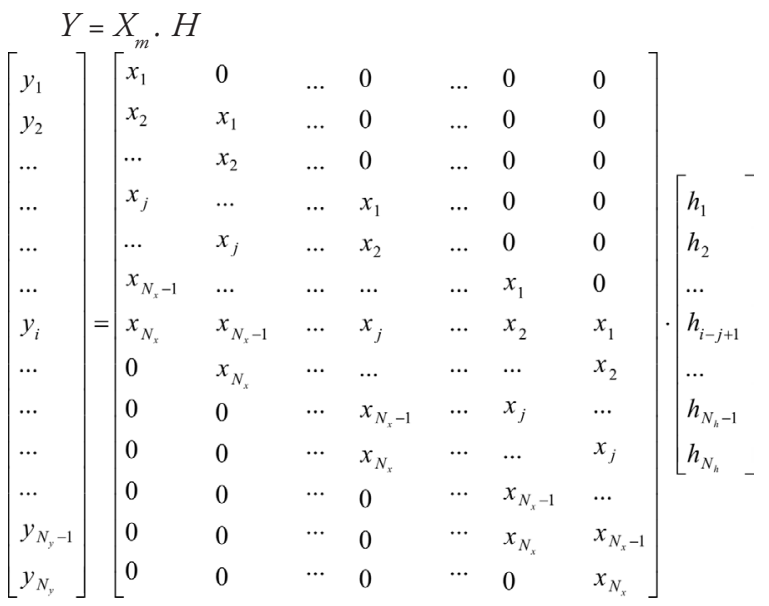

$$
\begin{aligned}
& Y=H_{m} \cdot X \\
& {\left[\begin{array}{l}
y_{1} \\
y_{2} \\
\ldots \\
\ldots \\
\ldots \\
\ldots \\
y_{i} \\
\ldots \\
\ldots \\
\ldots \\
\ldots \\
y_{N_{y}-1} \\
y_{N_{y}}
\end{array}\right]=\left[\begin{array}{lllllll}
h_{1} & 0 & \ldots & 0 & \ldots & 0 & 0 \\
h_{2} & h_{1} & \ldots . & 0 & \ldots & 0 & 0 \\
\ldots & h_{2} & \ldots & 0 & \ldots & 0 & 0 \\
h_{k} & \ldots & \ldots & h_{1} & \ldots & 0 & 0 \\
\ldots & h_{k} & \ldots & h_{2} & \ldots & 0 & 0 \\
h_{N_{h}-1} & \ldots & \ldots & \ldots & \ldots & h_{1} & 0 \\
h_{N_{h}} & h_{N_{h}-1} & \ldots & h_{k} & \ldots & h_{2} & h_{1} \\
0 & h_{N_{h}} & \ldots & \ldots & \ldots & \ldots & h_{2} \\
0 & 0 & \ldots & h_{N_{h}-1} & \ldots & h_{k} & \ldots \\
0 & 0 & \ldots & h_{N_{h}} & \ldots & \ldots & h_{k} \\
0 & 0 & \ldots & 0 & \ldots & h_{N_{h}-1} & \ldots \\
0 & 0 & \ldots & 0 & \ldots & h_{N_{h}} & h_{N_{h}-1} \\
0 & 0 & \ldots & 0 & \ldots & 0 & h_{N_{h}}
\end{array}\right] \cdot\left[\begin{array}{l}
x_{1} \\
x_{2} \\
\ldots \\
x_{i-k+1} \\
\ldots \\
x_{N_{x}-1} \\
x_{N_{x}}
\end{array}\right] }
\end{aligned}
$$

Os vetores e as matrizes das equaçóes 3 e 4 têm os totais de linhas e colunas seguintes:

$$
\begin{aligned}
Y \Rightarrow(N y, 1) ; & H_{m} \Rightarrow\left(N_{h}+N_{x}-1, N_{x}\right) ; & & X \Rightarrow\left(N_{x}, 1\right) ; \\
X_{m} & \Rightarrow\left(N_{x}+N_{h}-1, N_{h}\right) ; & & H \Rightarrow\left(N_{h}, 1\right)
\end{aligned}
$$

A experiência acumulada sobre os procedimentos iterativos por meio do cálculo matricial revelou uma lenta convergência para a solução final, fato explicado pelas correlaçôes existentes entre as colunas das matrizes. Nos trabalhos de Duband et al. (1993), Nalbantis et al. (1995) e Maia et al. (2006), uma versão modificada foi inicialmente apresentada, os aspectos de convergência em diferentes configuraçôes foram investigados e, finalmente, uma aplicaçấo ampliada da metodologia foi definida. Nesses estudos, o problema inicial de convergência lenta foi resolvido por uma simples combinação das equaçôes iniciais, trocando-as por vetores e matriz de diferenças, $\mathrm{dH}$ e $\mathrm{dH}_{\mathrm{m}}$ (vetor e matriz compostos por diferenças das ordenadas da função de transferência ou hidrograma unitário) e dY (vetor composto por diferenças das ordenadas das vazóes observadas). As correlações existentes no sistema matricial original são eliminadas dessa forma e a convergência para uma solução final do processo iterativo é alcançada após a execução de um número relativamente pequeno de iteraçốes.

As matrizes $\mathrm{X}_{\mathrm{m}}$ e $\mathrm{dH}_{\mathrm{m}}\left(\mathrm{dH}_{\mathrm{m}}\right.$ é usada na versáo modificada do sistema matricial) são em geral matrizes retangulares e a determinação dos vetores desconhecidos para cada uma das equaçóes, $\mathrm{dH}$ e $\mathrm{X}$, respectivamente, depende de um passo intermediário de multiplicação dessas equaçōes (ambos os lados) pelas matrizes transpostas respectivas, $\mathrm{d} H_{m}^{T}$ e $X_{m}^{T}$. Além do vetor $\mathrm{dY}$ alterado, as matrizes resultantes em cada caso são matrizes quadradas e portanto passíveis de inversão, viabilizando a identificação dos vetores otimizados, hidrograma unitário (expresso em diferenças de suas ordenadas), $\mathrm{dH}$, no primeiro caso, e precipitaçôes efetivas, X, no segundo caso. Em forma matricial simplificada, as equações 5 e 6 compóem o processo iterativo: os resultados obtidos para o hidrograma unitário (equaçáo 5) constituem o primeiro passo de cada iteração e alimentam a formaçáo das matrizes, do segunda passo da iteraçấo, viabilizando o cálculo do vetor de precipitaçôes efetivas e fechando os procedimentos da iteração em questão.

Dessa forma, a solução matricial correspondente é dada pelas equaçôes seguintes.

$$
\begin{aligned}
& d H=\left[X_{m}^{T} X_{m}\right]^{-1} X_{m}^{T} d Y \\
& X=\left[d H_{m}^{T} d H_{m}\right]^{-1} d H_{m}^{T} d Y
\end{aligned}
$$

As iteraçóes se sucedem até que um grau de convergência, definido previamente, seja alcançado, com a conseqüente determinação das precipitaçóes efetivas e do hidrograma unitário otimizados.

$\mathrm{Na}$ preparação do algoritmo que representa o processo iterativo descrito acima, controles sobre os valores resultantes de precipitaçấo efetivas e da função de transferência precisam ser inseridos para que a realidade física dos processos seja respeitada, conforme limites indicados na equação 1. Assim, os valores de precipitaçáo efetiva precisam ser positivos e inferiores aos valores de precipitaçáo total e a área sob a curva do hidrograma unitário deve ser unitária. 


\section{RESULTADOS E DISCUSSÃO}

\section{MEDIDAS DE DESCARGA E CURVA-CHAVE DO IGARAPÉ BOLIVIA}

As medidas de vazão do pequeno igarapé Bolívia foram realizadas desde outubro de 2004 com o objetivo de estabelecer a curva-chave desse curso d'água. No posto de medida, a bacia hidrográfica abrange uma área estimada de $11 \mathrm{Km}^{2}$. As profundidades na seção de medição náo ultrapassaram 1,5 $\mathrm{m}$, permitindo assim que as medições de vazão seguissem os procedimentos clássicos de medição a vau.

A distribuiçáo dos pontos de medidas, que definem a curva-chave para o igarapé Bolívia, é apresentada na figura abaixo. A curva de melhor ajuste dos pontos experimentais é dada pela equação:

$$
y=581,47 \cdot x^{2,64}
$$

em que y representa a descarga em litros/segundo e x o nível d'água no igarapé em metros.

\section{Curva-chave Ig. da Bolívia}

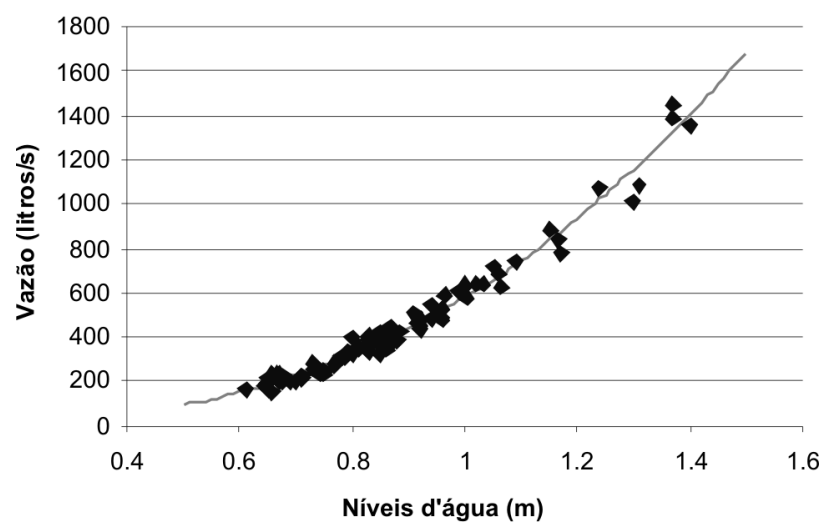

Figura 2 - Relação entre Níveis d'água e descarga líquida do igarapé Bolívia.

\section{CONVERGÊNCIA DO MÉTODO ITERATIVO DESCRITO}

Numa etapa preliminar de verificação do algoritmo preparado neste estudo, a convergência do processo iterativo descrito foi verificada para um evento sintético de chuva-vazão mostrado na Figura 3 e produzido a partir de um hidrograma unitário pré-estabelecido.

A escolha de um hidrograma com dois picos de escoamento tem o objetivo de situar o problema de otimizaçáo no contexto de funçóes objetivas regulares, contendo um único ponto de valor mínimo. Os casos de otimização dos processos hidrológicos, em sua grande maioria, enquadram-se nesse cenário mais simples de bom comportamento e regularidade da função objetiva.

As determinaçóes de hidrogramas unitários (e das precipitaçóes efetivas) em iteraçóes sucessivas são mostradas

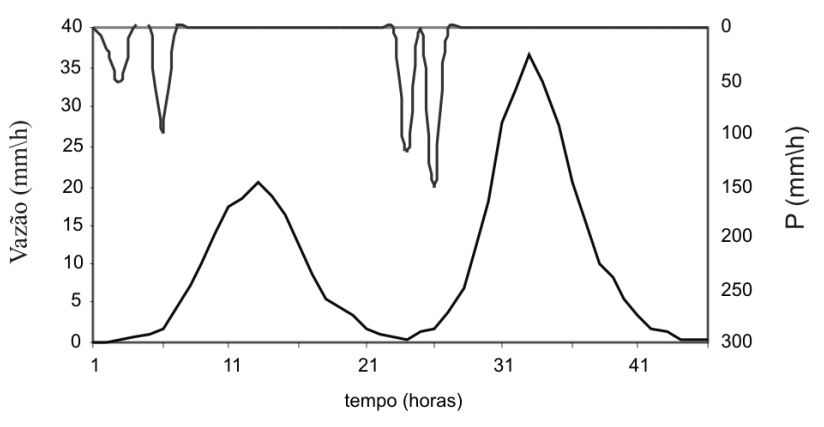

Figura 3 - Evento sintético Precipitação - vazão.

na Figura 4. Os cálculos são efetuados a partir de diferentes distribuiçóes iniciais de precipitação, assumidas na primeira iteração.

O evento sintético considerado tem cinco ordenadas de precipitaçâo. A análise de convergência explora a ausência ou presença de precipitação em cada uma dessas ordenadas temporais, considerando todas as combinaçóes possíveis dessas ordenadas tomadas uma a uma, duas a duas, etc, conforme indicado pelo número de curvas existentes em cada uma das colunas da Figura 4. Assim, os gráficos presentes na primeira coluna dessa figura mostram a convergência de cinco curvas, obtidas a partir de cada uma das diferentes combinaçóes possíveis de ocorrências de chuva em uma das cinco ordenadas temporais referidas acima; em seguida, os gráficos presentes na segunda coluna mostram a convergência de dez curvas, obtidas a partir de cada uma das diferentes combinações possíveis de ocorrências de chuva em duas das cinco ordenadas temporais; as outras três colunas estão associadas aos casos de ocorrência de chuvas com três, quatro e cinco ordenadas temporais, respectivamente. Em todos os gráficos, a curva adicional em negrito e traço contínuo representa o hidrograma unitário, estabelecido previamente.

Os resultados obtidos mostram que todas as distribuiçôes de chuvas com três ou mais ordenadas convergem com um número de iteraçôes inferior a trinta. Dentre as distribuições de chuva restantes, apenas seis casos não convergem após a execuçấo de trinta iteraçóes. O caso extremo associado à distribuição de chuva inicial com uma única ordenada coincidindo com a ocorrência da menor chuva observada converge após setenta iteraçóes.

\section{DETERMINACÕES DO HIDROGRAMA UNITÁRIO E DAS PRECIPITAÇÕES EFETIVAS - IGARAPÉ BOLIIVIA.}

No período de observação, entre agosto de 2005 e agosto de 2006, foram selecionados os eventos de precipitaçáo descarga, resultando num conjunto diversificado de quarenta e três hidrogramas observados: eventos com picos isolados de escoamento; eventos com dois picos de escoamento; eventos com três picos e um número de eventos que apresentaram 
ACTA

Modelo de escoamento superficial em bacia experimental da

AMAZONICA

Reserva Florestal Adolpho Ducke

$\mathrm{N}_{\mathrm{x}}=1 \rightarrow C_{5}^{l}$

Iterações

1
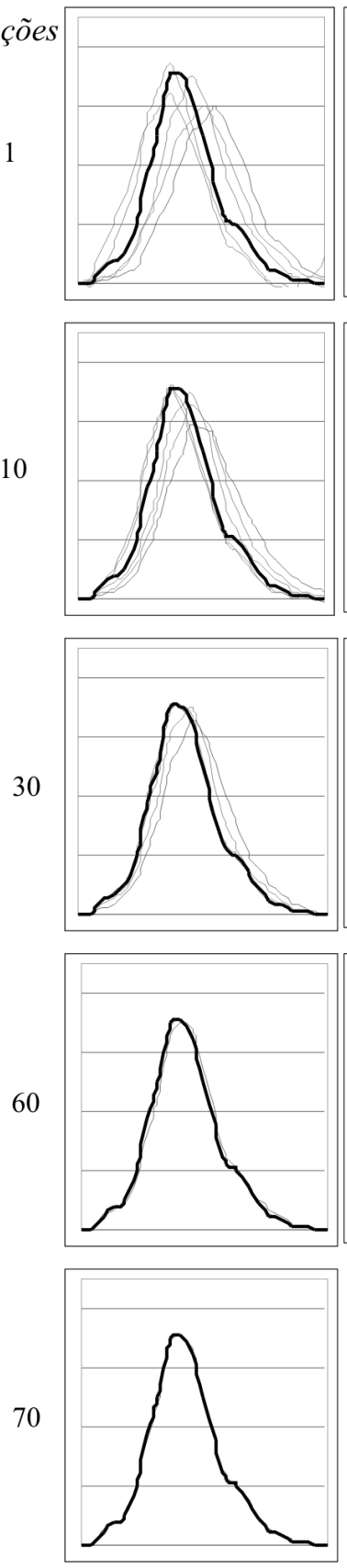

$\mathrm{N}_{\mathrm{x}}=2 \rightarrow C_{5}^{2}$
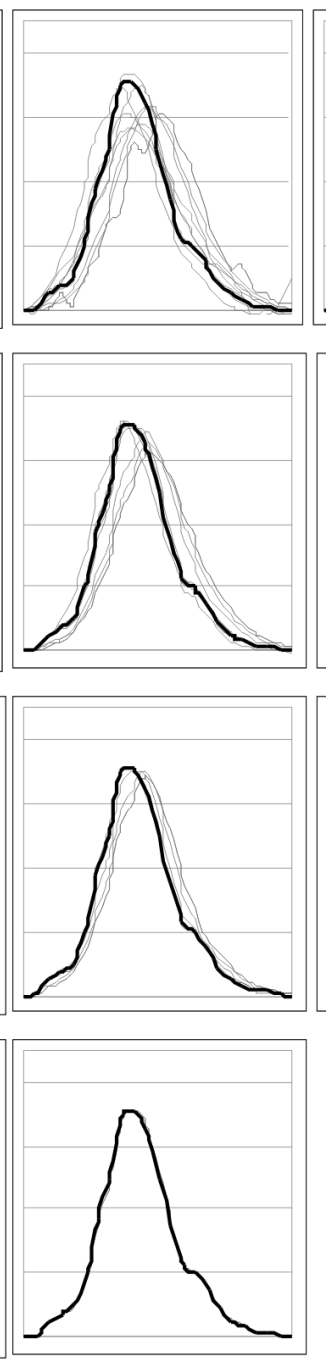
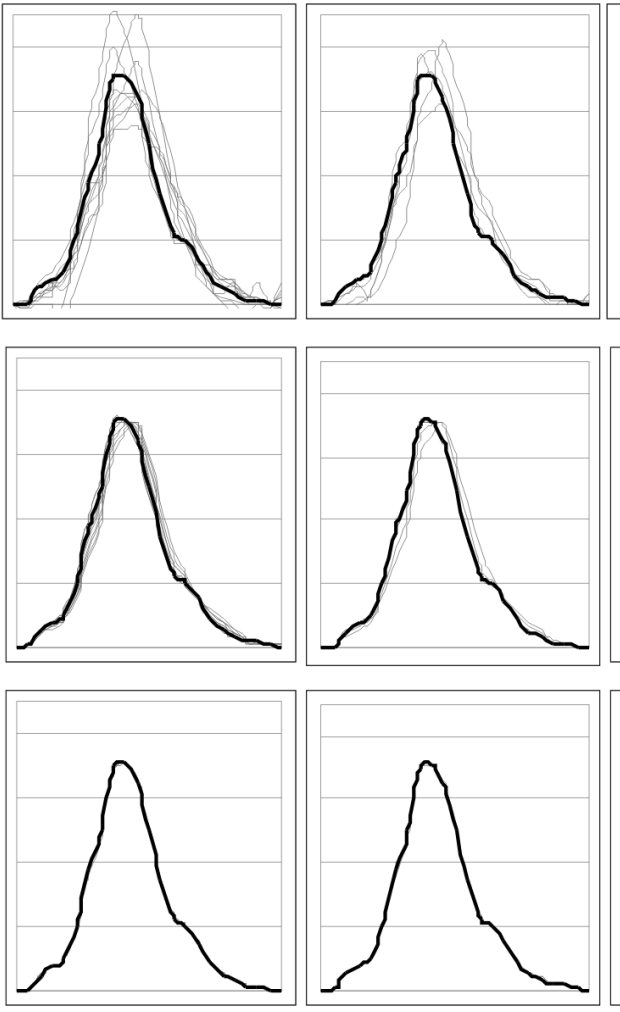

$\mathrm{N}_{\mathrm{x}}=4 \rightarrow C_{5}^{4}$

$\mathrm{N}_{\mathrm{x}}=5 \rightarrow C_{5}^{5}$
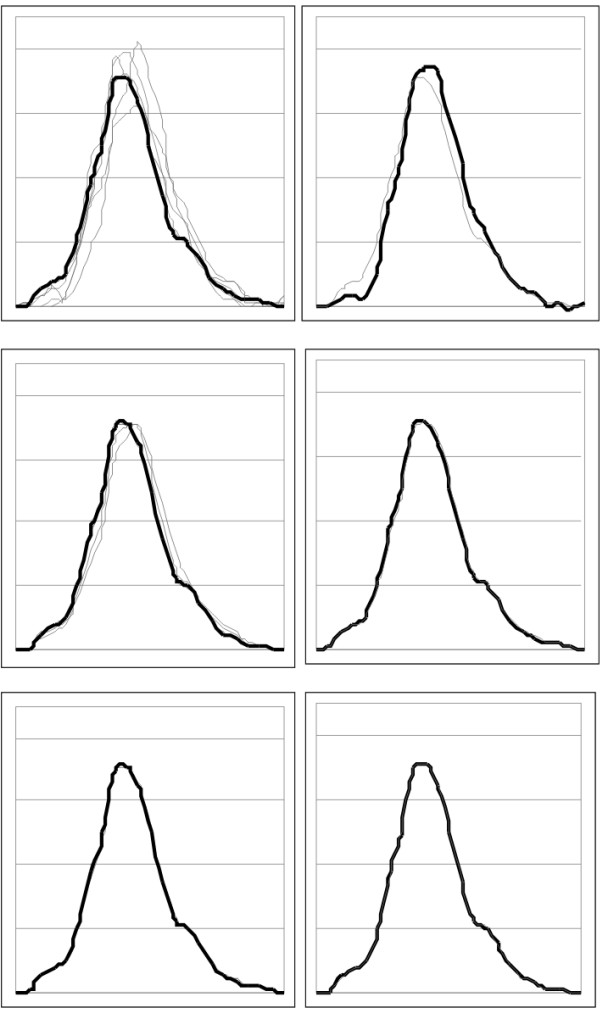

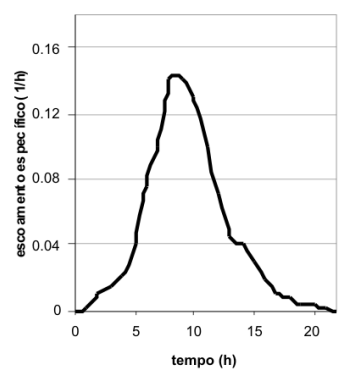

Figura 4 - Configurações de precipitações iniciais e convergência do processo iterativo. (gráfico isolado indica as escalas de tempo - eixo x, e de escoamento específico, eixo y).

912 VOL. 39(4) 2009: 907 - 922 - MARQUES FILHO et al. 
quatro ou mais picos de escoamento no igarapé Bolívia. Nesse período de observação, houve apenas um evento extremo de precipitação, descartado em razão do transbordamento na seção do curso d'água

As características principais desses 43 eventos são mostradas na Tabela 1 . A organizaçáo dos eventos nessa tabela segue a ordem crescente de escoamento superficial produzido, expresso pela precipitaçáo efetiva calculada.

Verifica-se, de acordo com essa tabela, que uma quantidade relativamente pequena da precipitação total (coeficiente de escoamento $=12,3 \%$ ) deixa a bacia em forma de escoamento superficial. Do montante que náo sai desta forma, uma parte retorna à atmosfera pelo processo de evapotranspiraçáo e o restante armazenado nas camadas do solo da bacia alimenta o escoamento subterrâneo nos igarapés, sobretudo nos períodos de pouca chuva. Os mecanismos de armazenamento e de liberaçáo de águas nas camadas do solo precisam ainda ser estudados, procurando determinar a profundidade da coluna de solo que tenha influência mais direta no escoamento básico. Fajardo et al. (2008) perceberam a formaçáo de pelo menos duas camadas bem distintas de solo na mesma área de estudo, sendo a mais superficial com espessura de aproximadamente um metro. Esta camada superior apresenta uma condutividade hidráulica mais elevada que a inferior, dando um escoamento mais rápido à água da chuva infiltrada. Não se sabe se o armazenamento e a liberação de água para o igarapé são influenciados apenas por estas duas camadas ou se existem outros estratos que atuam nesses processos. Esta informação contribuiria muito para entender a fragilidade destes sistemas que ao longo dos anos vêm sofrendo interferências antrópicas, sem que se conheça uma forma segura de manejar estas bacias, evitando causar grandes interferências nos mecanismos que fazem com que os igarapés da região sejam perenes.

Numa ordenação dos resultados de otimização obtidos, considerando eventos com picos isolados, eventos com picos duplos e eventos com picos múltiplos, as representaçôes respectivas são mostradas nas Figuras 5, 6 e 7, abaixo. Na parte superior de cada gráfico é mostrada a distribuição temporal de chuva dos eventos; e na parte inferior os hidrogramas observado e calculado.

O hidrograma unitário médio obtido para o igarapé Bolívia é mostrado na Figura 8, junto com os hidrograms unitários parciais associados aos hidrogramas de picos isolados, picos duplos e picos múltiplos.

Um contraste marcante entre as determinações individuais por eventos de diferentes classes é mostrado nas figuras correspondentes: as determinaçôes associadas aos hidrogramas observados com picos isolados apresentam uma grande dispersáo, refletida tanto na variabilidade do tempo de ocorrência dos picos dos hidrogramas unitários individuais, como nas flutuaçóes das curvas representativas correspondentes.
Tabela 1 - Resumo dos Eventos - Hidrogramas 1-43.

\begin{tabular}{|c|c|c|c|c|c|}
\hline Ordem & Data & Hora & $\mathrm{Pt}(\mathrm{mm})$ & $\mathrm{Pe}(\mathrm{mm})$ & Cs (adim) \\
\hline 1 & $13 / 10 / 2005$ & $16 \mathrm{~h}$ & 12,76 & 0,73 & 0,057 \\
\hline 2 & $28 / 06 / 2006$ & $7 \mathrm{~h}$ & 7,07 & 0,88 & 0,124 \\
\hline 3 & $25 / 08 / 2006$ & $14 \mathrm{~h}$ & 10,50 & 1,17 & 0,111 \\
\hline 4 & $28 / 03 / 2006$ & $14 \mathrm{~h}$ & 14,73 & 1,29 & 0,088 \\
\hline 5 & $25 / 06 / 2006$ & $6 \mathrm{~h}$ & 10,50 & 1,33 & 0,154 \\
\hline 6 & $30 / 08 / 2006$ & $15 \mathrm{~h}$ & 4,82 & 1,35 & 0,280 \\
\hline 7 & $03 / 11 / 2005$ & $5 \mathrm{~h}$ & 23,24 & 1,58 & 0,068 \\
\hline 8 & $10 / 11 / 2005$ & $15 \mathrm{~h}$ & 11,25 & 1,62 & 0,144 \\
\hline 9 & $12 / 03 / 2006$ & $3 \mathrm{~h}$ & 51,73 & 1,62 & 0,031 \\
\hline 10 & $16 / 11 / 2005$ & $11 \mathrm{~h}$ & 42,84 & 1,90 & 0,044 \\
\hline 11 & 02/08/2006 & $18 \mathrm{~h}$ & 22,26 & 1,98 & 0,089 \\
\hline 12 & $19 / 06 / 2006$ & $5 \mathrm{~h}$ & 23,35 & 2,21 & 0,095 \\
\hline 13 & $10 / 06 / 2006$ & $8 \mathrm{~h}$ & 19,98 & 2,21 & 0,111 \\
\hline 14 & $30 / 03 / 2006$ & $18 \mathrm{~h}$ & 42,94 & 2,52 & 0,059 \\
\hline 15 & $30 / 07 / 2006$ & $11 \mathrm{~h}$ & 36,01 & 2,62 & 0,073 \\
\hline 16 & $12 / 07 / 2006$ & $13 \mathrm{~h}$ & 15,95 & 2,62 & 0,164 \\
\hline 17 & 03/06/2006 & $14 \mathrm{~h}$ & 12,93 & 2,65 & 0,205 \\
\hline 18 & $21 / 11 / 2005$ & $8 \mathrm{~h}$ & 27,68 & 2,79 & 0,101 \\
\hline 19 & $02 / 04 / 2006$ & $10 \mathrm{~h}$ & 28,20 & 2,80 & 0,099 \\
\hline 20 & $30 / 11 / 2005$ & $13 \mathrm{~h}$ & 32,95 & 3,28 & 0,100 \\
\hline 21 & $02 / 01 / 2006$ & $10 \mathrm{~h}$ & 5,59 & 3,31 & 0,592 \\
\hline 22 & $30 / 05 / 2006$ & $11 \mathrm{~h}$ & 31,75 & 3,35 & 0,106 \\
\hline 23 & $30 / 12 / 2006$ & $15 \mathrm{~h}$ & 40,63 & 3,43 & 0,084 \\
\hline 24 & $04 / 12 / 2005$ & $6 \mathrm{~h}$ & 70,26 & 3,49 & 0,050 \\
\hline 25 & $16 / 03 / 2006$ & $14 \mathrm{~h}$ & 31,99 & 3,70 & 0,116 \\
\hline 26 & $22 / 04 / 2006$ & $15 \mathrm{~h}$ & 20,29 & 3,84 & 0,189 \\
\hline 27 & $17 / 12 / 2005$ & $11 \mathrm{~h}$ & 32,23 & 4,42 & 0,137 \\
\hline 28 & $25 / 05 / 2006$ & $4 \mathrm{~h}$ & 25,01 & 4,47 & 0,179 \\
\hline 29 & $18 / 01 ; 2006$ & $18 \mathrm{~h}$ & 51,84 & 4,48 & 0,086 \\
\hline 30 & 03/05/2006 & $4 \mathrm{~h}$ & 74,14 & 4,48 & 0,060 \\
\hline 31 & $22 / 03 / 2006$ & $13 \mathrm{~h}$ & 50,31 & 4,63 & 0,092 \\
\hline 32 & $05 / 11 / 2005$ & $12 \mathrm{~h}$ & 77,20 & 4,82 & 0,062 \\
\hline 33 & $18 / 04 / 2006$ & $15 \mathrm{~h}$ & 32,67 & 5,21 & 0,159 \\
\hline 34 & $12 / 12 / 2005$ & $15 \mathrm{~h}$ & 39,14 & 5,30 & 0,135 \\
\hline 35 & $06 / 04 / 2006$ & $10 \mathrm{~h}$ & 52,06 & 6,32 & 0,121 \\
\hline 36 & $13 / 04 / 2006$ & $11 \mathrm{~h}$ & 71,18 & 7,42 & 0,104 \\
\hline 37 & $25 / 04 / 2006$ & $7 \mathrm{~h}$ & 46,12 & 7,46 & 0,162 \\
\hline 38 & $19 / 11 / 2005$ & $16 \mathrm{~h}$ & 89,44 & 7,90 & 0,088 \\
\hline 39 & $23 / 11 / 2005$ & $13 \mathrm{~h}$ & 113,00 & 11,38 & 0,101 \\
\hline 40 & $27 / 01 / 2006$ & $14 \mathrm{~h}$ & 99,48 & 11,52 & 0,116 \\
\hline 41 & $26 / 02 / 2006$ & $8 \mathrm{~h}$ & 154,50 & 17,98 & 0,116 \\
\hline 42 & $07 / 05 / 2006$ & $11 \mathrm{~h}$ & 198,96 & 19,07 & 0,096 \\
\hline \multirow[t]{2}{*}{43} & $05 / 02 / 2006$ & $13 \mathrm{~h}$ & 195,34 & 23,34 & 0,119 \\
\hline & & & & & $\begin{array}{l}\text { Cs médio } \\
=0,123\end{array}$ \\
\hline
\end{tabular}



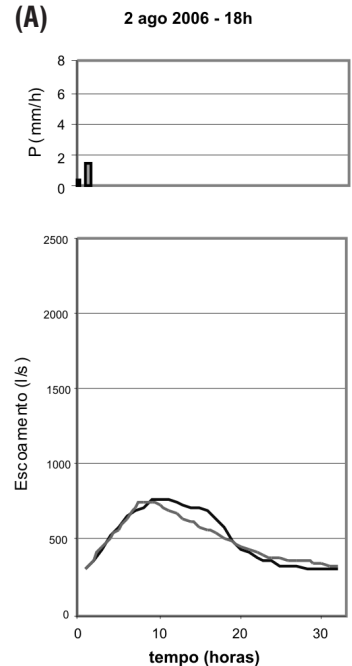

(B)

2 jan 2006 - 10h
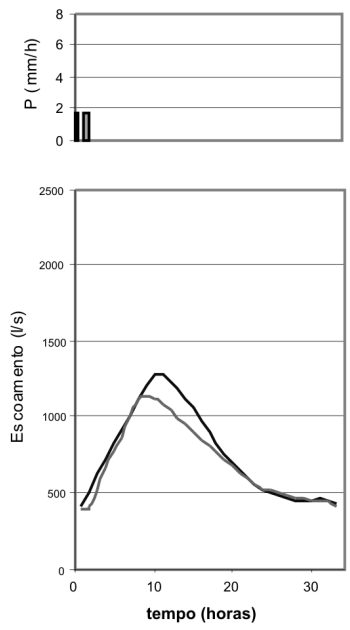

(C)
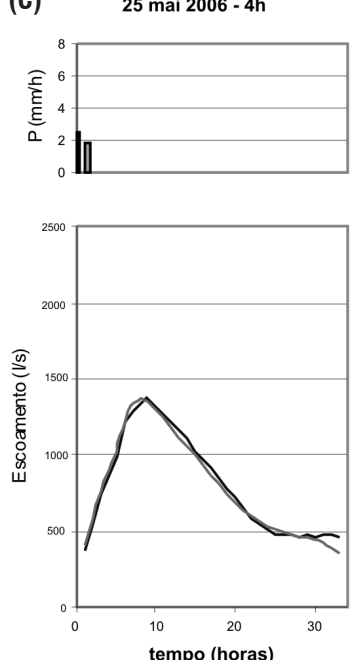

16 nov $2005-11 \mathrm{~h}$
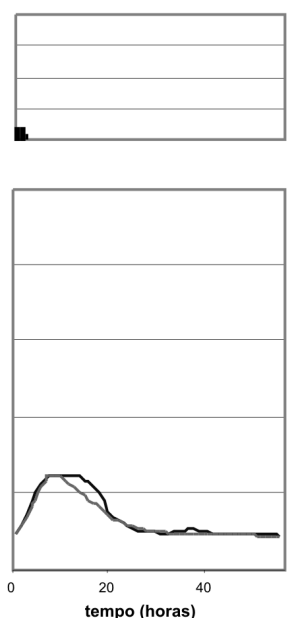

22 abr 2006 15h
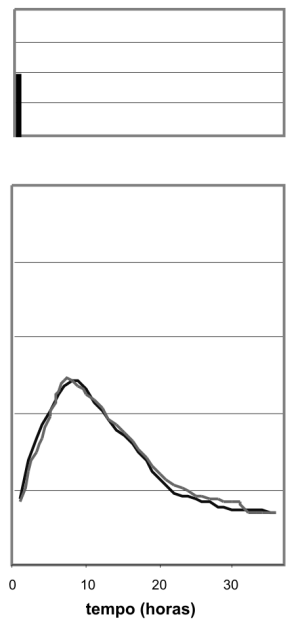

18 jan 2006 - 18h
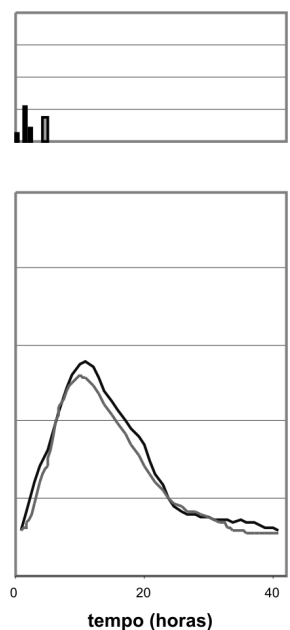

19 jun $2006-5 h$
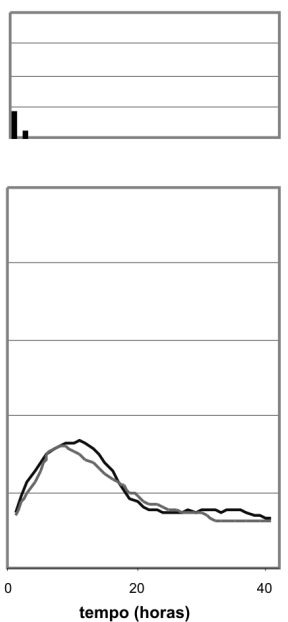

30 dez $2006-13 h$
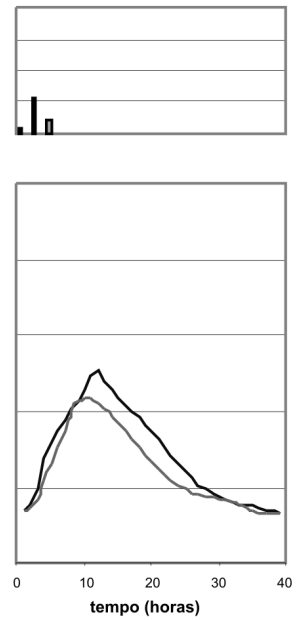

12 dez 2005 - 15h
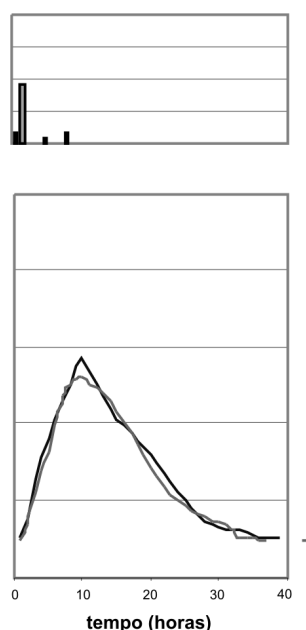

10 jun $2006-8 h$
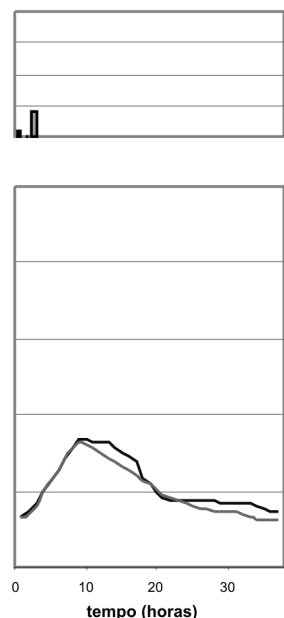

17 dez $2005-11 \mathrm{~h}$
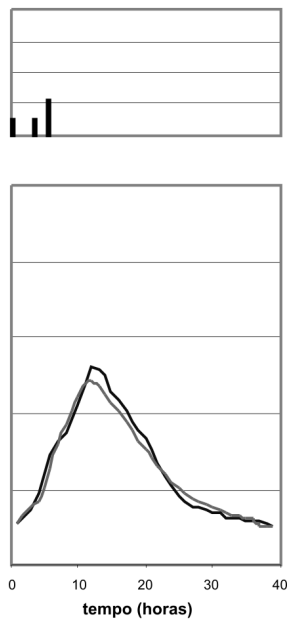

25 abr $2006-7 \mathrm{~h}$
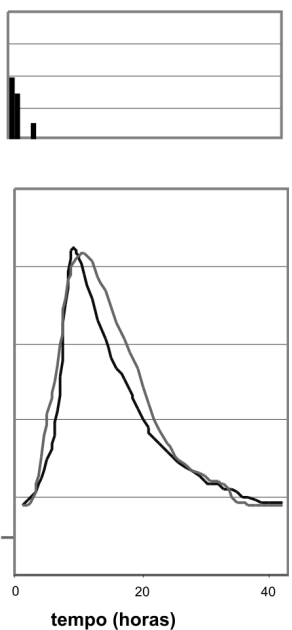

Figura 5 - Eventos de precipitação - descarga no igarapé Bolívia. - Picos Isolados.(a), (b), (c). ( - ) hidrograma observado; ( - ) Hidrograma calculado. 
(A)
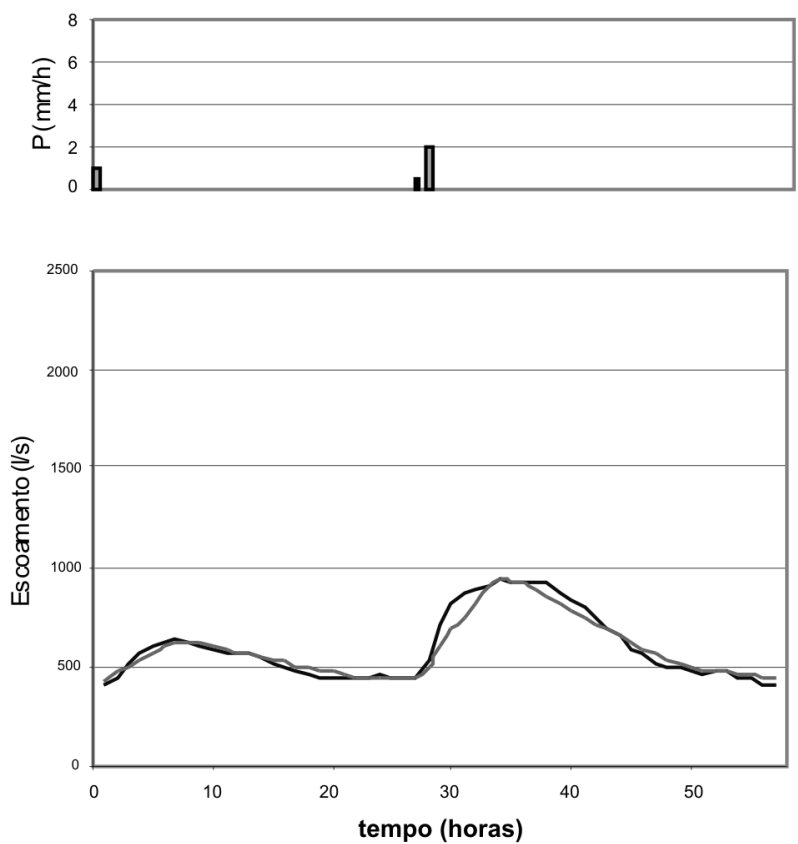

16 mar 2006 - 14h
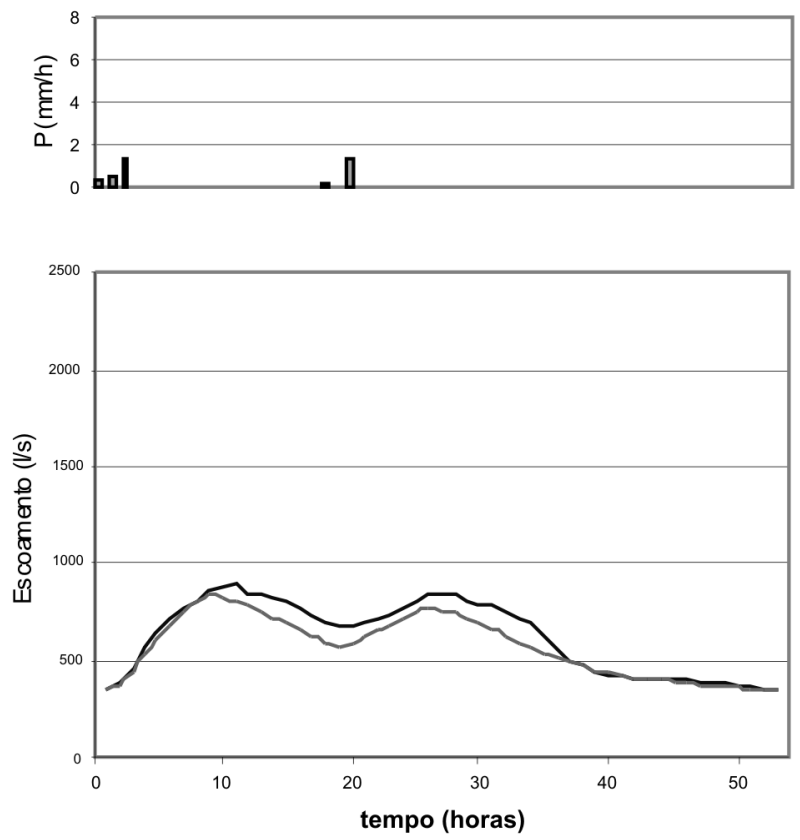

30 nov $2005-13 h$
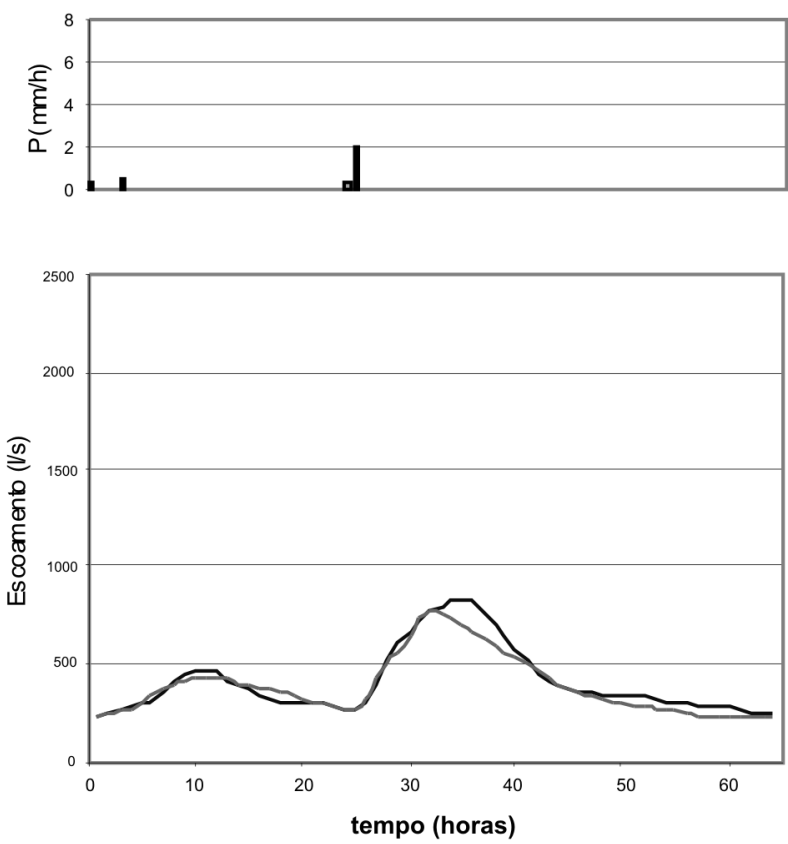

18 abr $2006-15 h$
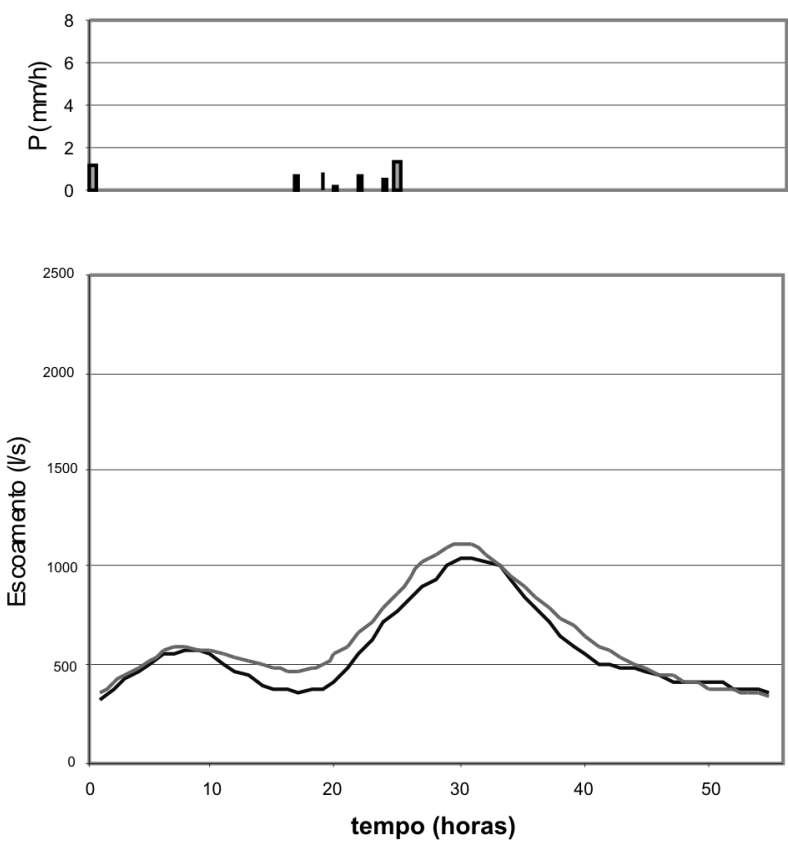
(B)
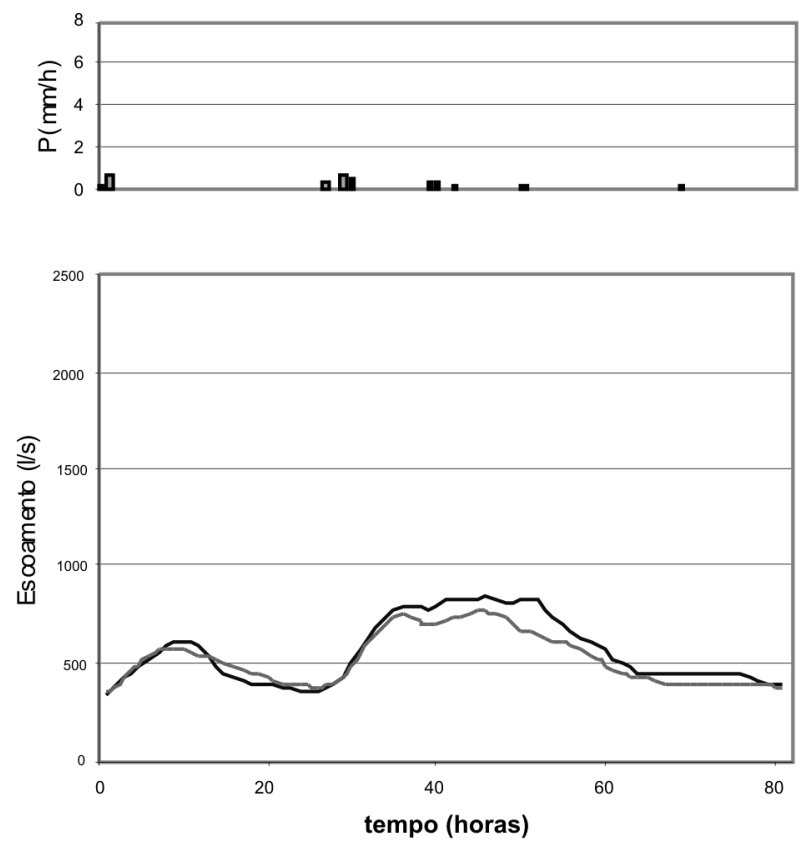

5 nov 2005 - 12h
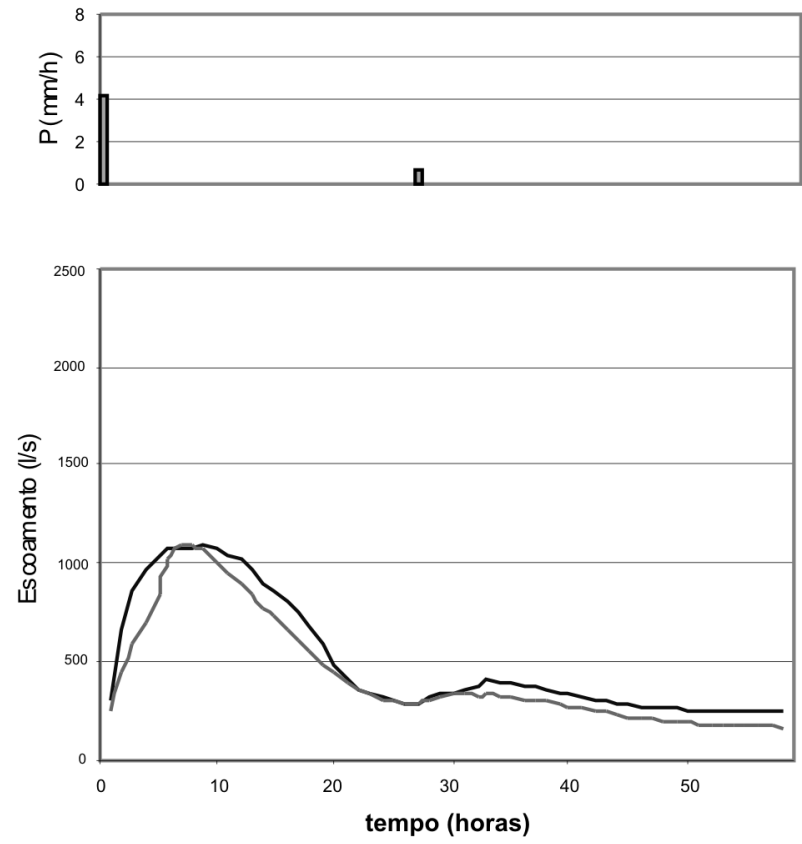

3 mai 2006 - 4h
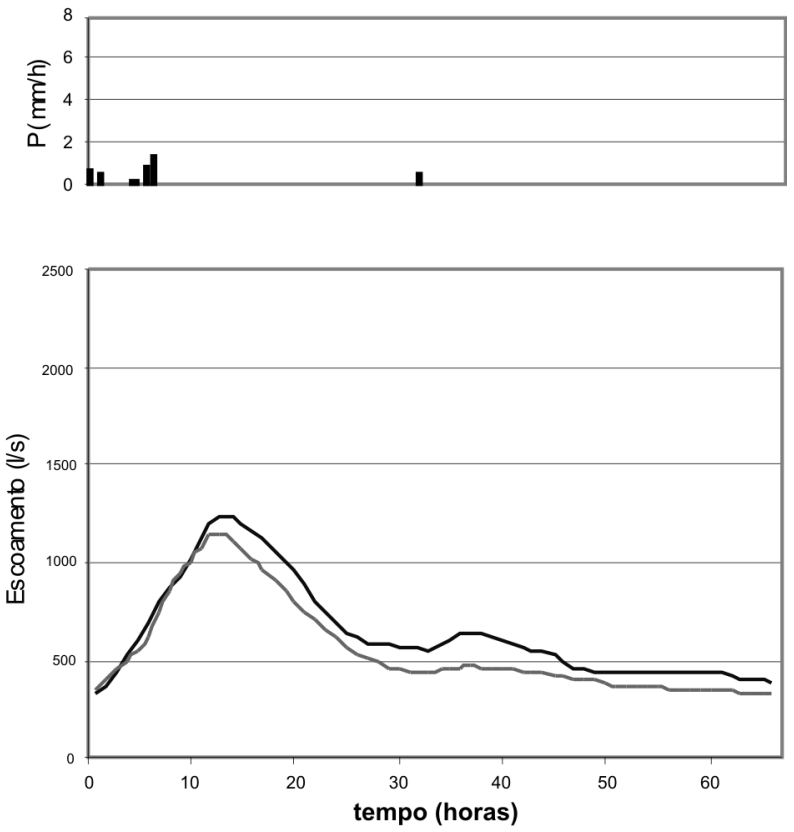

6 abr $2006-10 h$
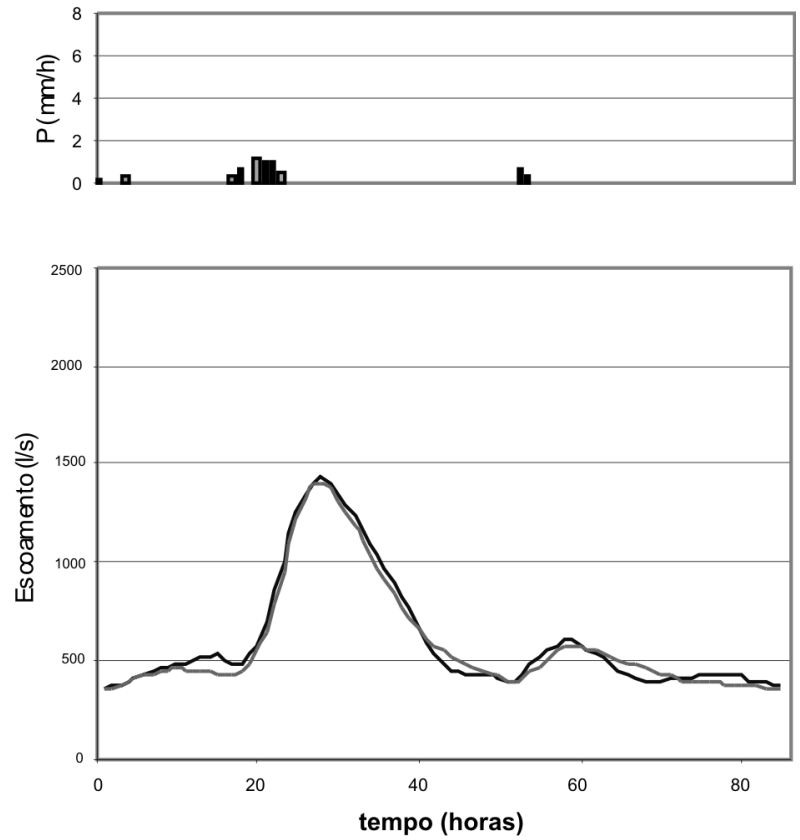
(C)
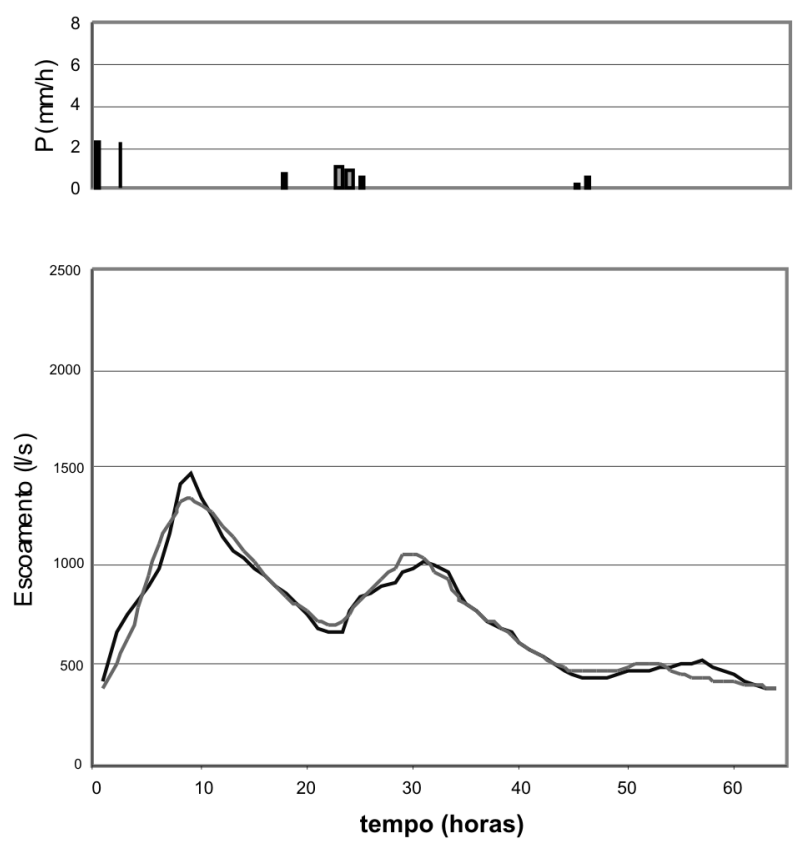

23 nov $2005-13 h$
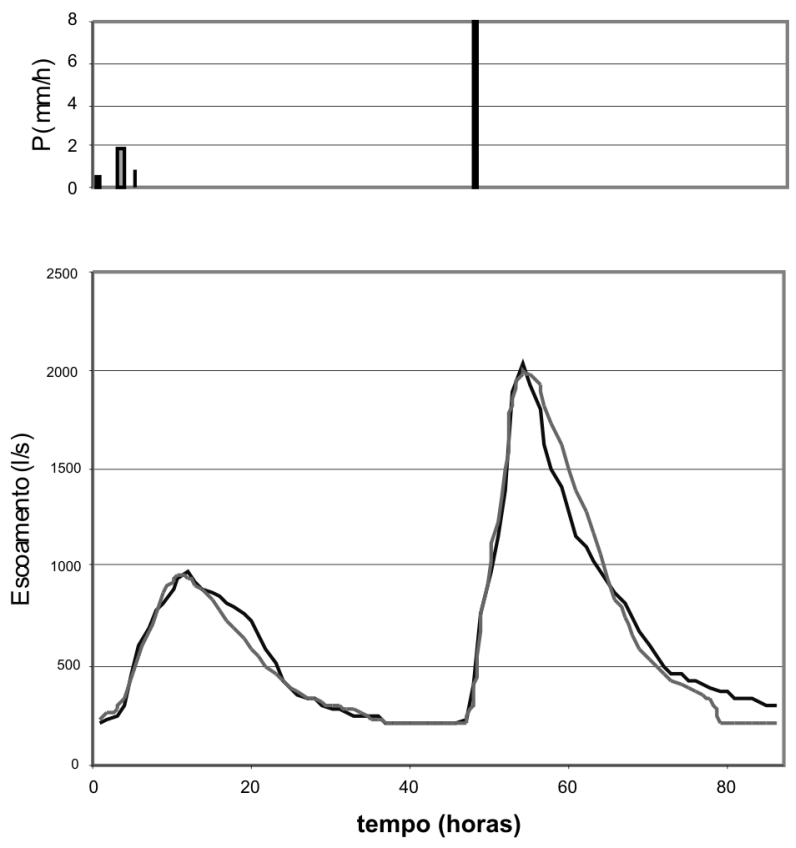

13 abr $2006-11 h$
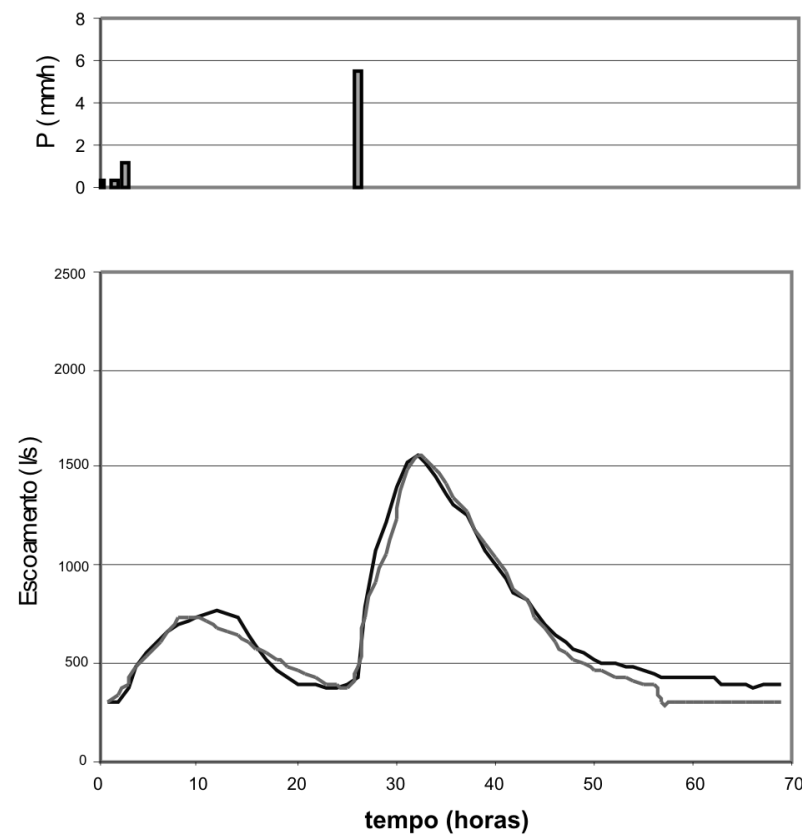

Figura 6 - Eventos de precipitação - descarga no igarapé Bolívia. Picos Duplos. (a), (b), (c). ( - ) hidrograma observado; ( - ) Hidrograma calculado. 
ACTA

AMAZONICA
Modelo de escoamento superficial em bacia experimental da

Reserva Florestal Adolpho Ducke
(A)
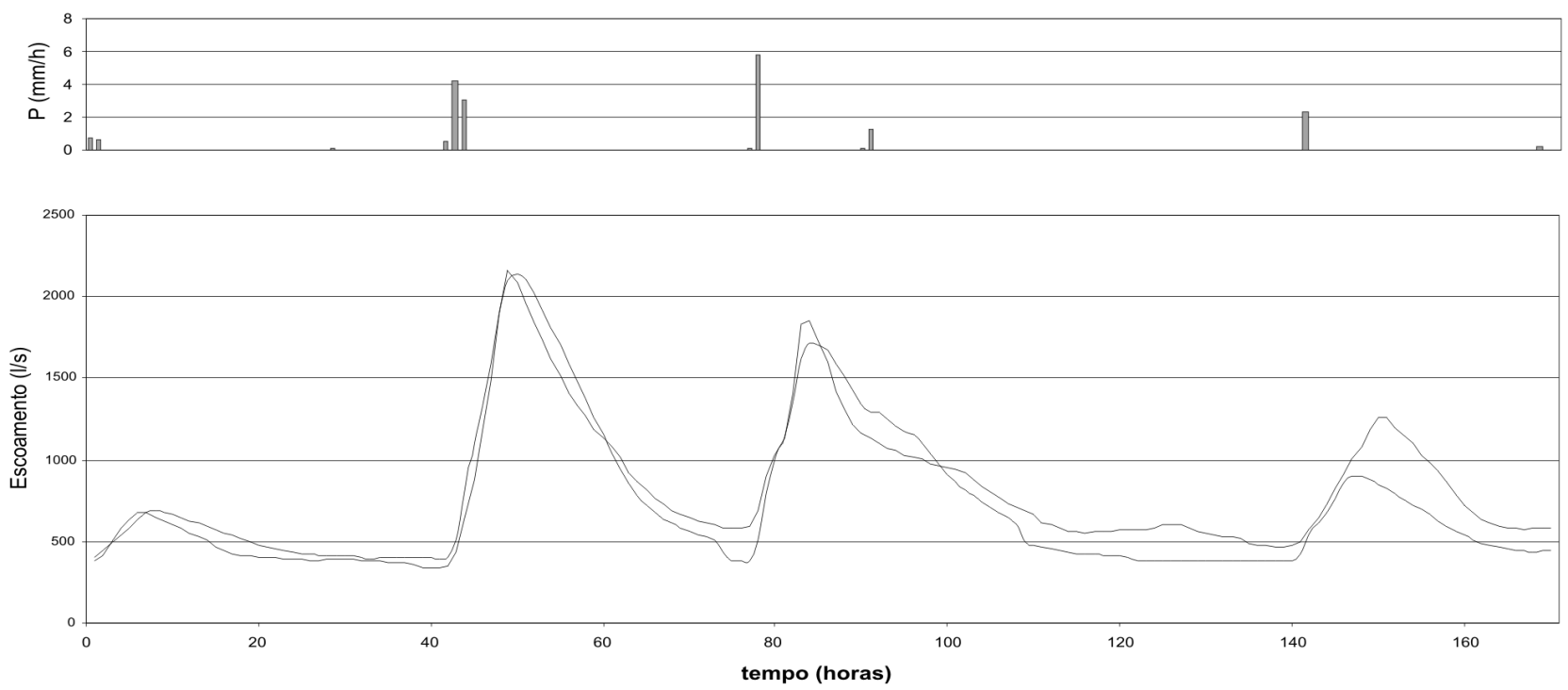

27 jan $2006-14 h$
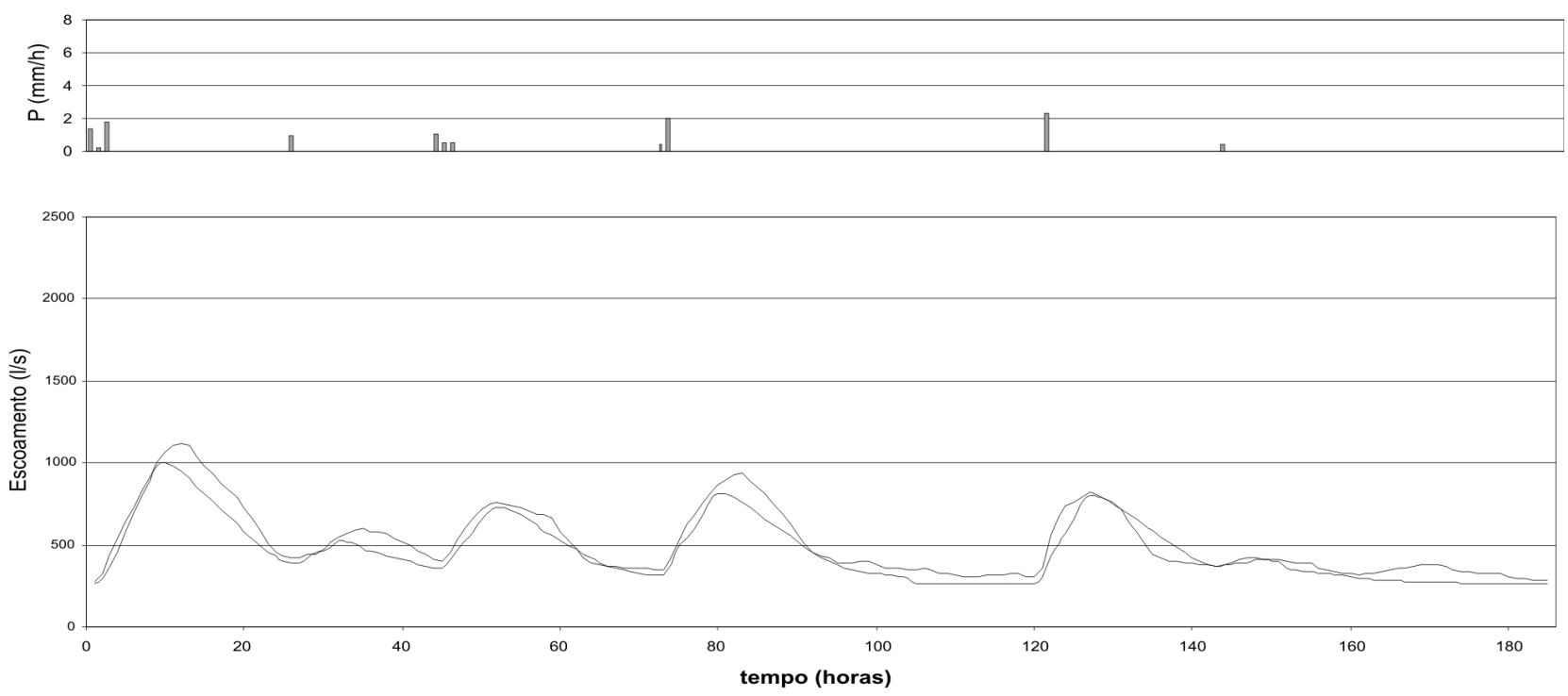

918 VOL. 39(4) 2009: 907 - 922 - MARQUES FILHO et al. 

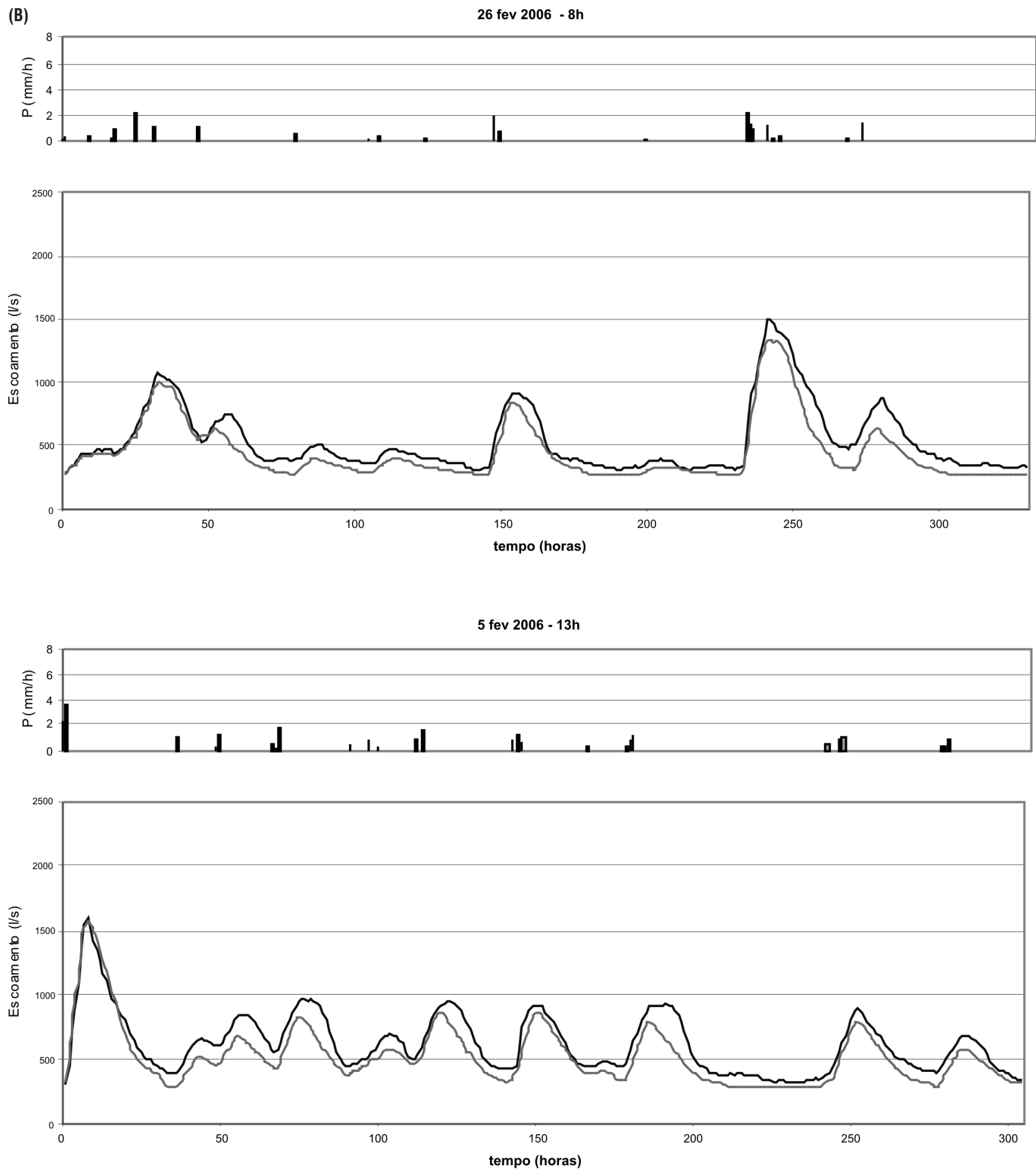

Figura 7 - Eventos de precipitação - descarga no igarapé Bolívia. - Picos Múltiplos. (a). (b). ( - ) hidrograma observado; ( - ) Hidrograma calculado. 
Modelo de escoamento superficial em bacia experimental da
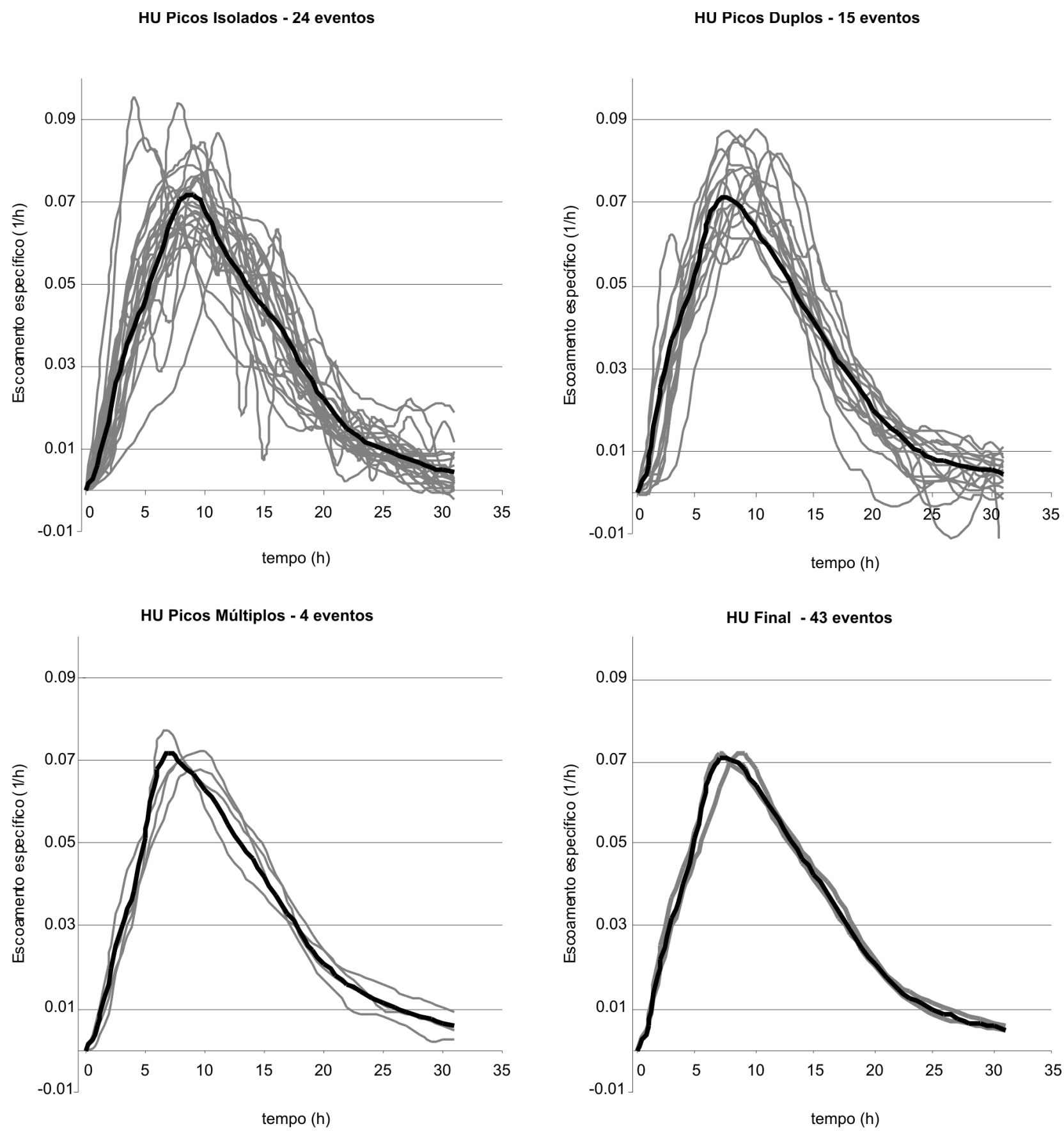

Figura 8 - Hidrograma unitário médio para o igarapé Bolívia e sua variação em função dos hidrogramas observados. 
Essa dispersão ocorre nas determinaçóes associadas aos hidrogramas observados com picos duplos, mas de forma bastante atenuada, especialmente no aspecto de regularidade das curvas representativas dos hidrogramas unitários. Na classe dos hidrogramas com picos múltiplos, mesmo que o número de eventos seja bem reduzido, a tendência de regularidade é consolidada pela ausência de qualquer flutuação nas curvas, restando apenas uma pequena variabilidade no tempo de ocorrências dos picos dos hidrogramas unitários. A síntese dos 43 eventos mostra o hidrograma unitário final, abrangendo todas as informaçóes existentes e comparado aos hidrogramas unitários médios determinados para cada uma das classes descritas acima. As pequenas variaçóes entre as curvas assim estabelecidas indicam que a determinação de um hidrograma unitário médio para uma bacia hidrográfica depende essencialmente da quantidade de informação disponível para a sua determinação. As determinaçôes parciais tendem a convergir para uma mesma curva representativa do hidrograma unitário da bacia, não apresentando dependência em relação às classes originais dos hidrogramas observados.

Uma comparação preliminar dos resultados apresentados neste estudo com os resultados de simulação hidrológica obtidos para a Bacia Modelo - ZF2. (Marques Filho et al., 1983) pode ser sintetizada da seguinte forma: (i) os procedimentos de otimização são similares do ponto de vista conceitual nos dois casos, com a diferença de que no estudo da Bacia Modelo apenas o hidrograma unitário é determinado; (ii) a área da bacia associada ao PF1 da Bacia Modelo (11,5 $\mathrm{Km}^{2}$ ) é da mesma ordem de grandeza daquela do Igarapé Bolívia; (iii) a quantidade e o tipo de eventos selecionados na Bacia Modelo são bastante inferiores ao conjunto de eventos do presente estudo; (iv) os tempos de ocorrência dos picos e a duração total dos hidrogramas unitários para o Igarapé Bolívia e para o PF1 da Bacia Modelos são da mesma ordem de grandeza, tempo de ocorrência do pico: -7 horas e 5 horas; duração total do hidrograma unitário: 31 horas e 28 horas, respectivamente. A similaridade de resultados obtidos para pequenas bacias hidrográficas na região sugere a realização de novos estudos, utilizando o método descrito, na busca de condições favoráveis à simulação hidrológica em diferentes ambientes florestais.

\section{CONCLUSÃO}

O hidrograma unitário médio para o igarapé Bolívia foi obtido neste estudo com o aproveitamento de quarenta e três eventos de precipitaçáo-escoamento observados na bacia. O algoritmo computacional de otimização criado para a determinação dessa função constitui um artefato numérico iterativo com convergência verificada para diferentes configuraçóes iniciais assumidas de precipitação. A grande dispersão entre as curvas que representam os hidrogramas unitários calculados a partir de hidrogramas com picos isolados indica a necessidade de um grande número de eventos para gerar um hidrograma médio representativo, em contraste aos eventos complexos em que uma pequena quantidade ou mesmo um único evento distribuído ao longo do tempo já é suficiente para gerar um hidrograma unitário médio para a bacia. As precipitaçóes efetivas calculadas para todos os eventos representam também um conjunto de informação sobre a infiltração ocorrida em cada evento e próprio para investigação futura sobre modelos de infiltração no solo sob floresta primária.

\section{AGRADECIMENTOS}

Os autores agradecem aos técnicos da Coordenação de Pesquisas em Clima e Recursos Hídricos do INPA: Afonso Ligório da Motta, Osvaldo Pinto de Albuquerque, Pedrinho de Almeida Paiva e Sérgio Magno Valério de Souza pela preparação, instalação e operaçáo dos sistemas de medidas na bacia experimental; ao bolsista PCI do SIGLAB/CPCS Frederico Octávio Ribeiro Fonseca pela concepção de imagem de localização da Reserva Ducke. Este estudo está inserido no projeto de pesquisa: Regime hidrológico e monitoramento ambiental de bacia hidrográfica em reserva florestal sob crescente pressão antrópica em seu entorno. Ref.: CTHIDRO/ CNPQ - 50.3677/03-5.

\section{BIBLIOGRAFIA CITADA}

Diskin, M. H.; Boneh, A. 1975. Determination of an optimal IUH for linear time invariant systems from multi-storms records. Journal of Hydrology, 24:57-76.

Dooge, J. C. I. 1959. A general theory of the unit hydrograph. Journal of Geophysical Research, 64(2): 241- 256.

Dooge, J. C. I. 1973. Linear theory of hydrological systems. Techical Bulletin no. 1468, A.R.S, U.S. Department of Agriculture, Washington, D.C. 327p.

Duband, D.; Obled, C.; Rodriguez, J. Y. 1993. Unit Hydrograph revisited: an alternate iterative approach to $\mathrm{UH}$ and effective precipitation identification. Journal of Hydrology, 150: 115149.

Fajardo, J.D; Ferreira, S. J. F.; Miranda, S. A. F.; Marques Filho, A. O. 2008. Características hidrológicas do solo saturado na reserva florestal Adolpho Ducke - Amazônia Central. Árvire (artigo submetido em 2008)

Hewlett, J. D.; Hibbert, A. R. 1967. Factors affecting the response of small watersheds to precipitation in humid areas. In: Sopper, W. E.; Lull, H. W. (Eds). Forest Hydrology. Pergamon Press. Oxford. p. 275-290.

Marques Filho, A. O.; Dallarosa, R. G. 2000. Interceptação de radiação solar e distribuição espacial de área foliar em floresta de terra firme da Amazônia Central. Acta Amazonica, 30(3):453470 . 
Marques Filho, A. O.; Ribeiro, M. N. G.; Santos, J. M.; Salati, E. 1982. Simulação de escoamento superficial em bacias representativas na Amazônia. Acta Amazonica, 12(3) Suplemento:29-37.

Maia, A. N.; Amaral, I. R.; Versiani, B. R. 2006. Metodologia DPFT de identificação do hidrograma unitário e das precipitaçóes efetivas: estudo de caso para a bacia hidrográfica de Juatuyba MG. Revista Brasileira de Recursos Hidricos, 11(1): 79-90.

Nalbantis, I.; Obled, C.; Rodriguez, J. Y. 1995. Unit hydrograph and effective precipitation identification. Journal of Hydrology, 168: $127-157$.

Nash, J. E. 1959. Systematic determination of unit hydrograph parameters. Journal of Geophysical Research, 64(1): 111- 115.
Newton, D. W.; Vinyard, J. W. 1967. Computer-determined unit hydrograph from floods. Journal of the Hydraulics Division ASCE, 93(Hy5): 219-235.

Recebido em 08/04/2009

Aceito em 27/06/2009 